
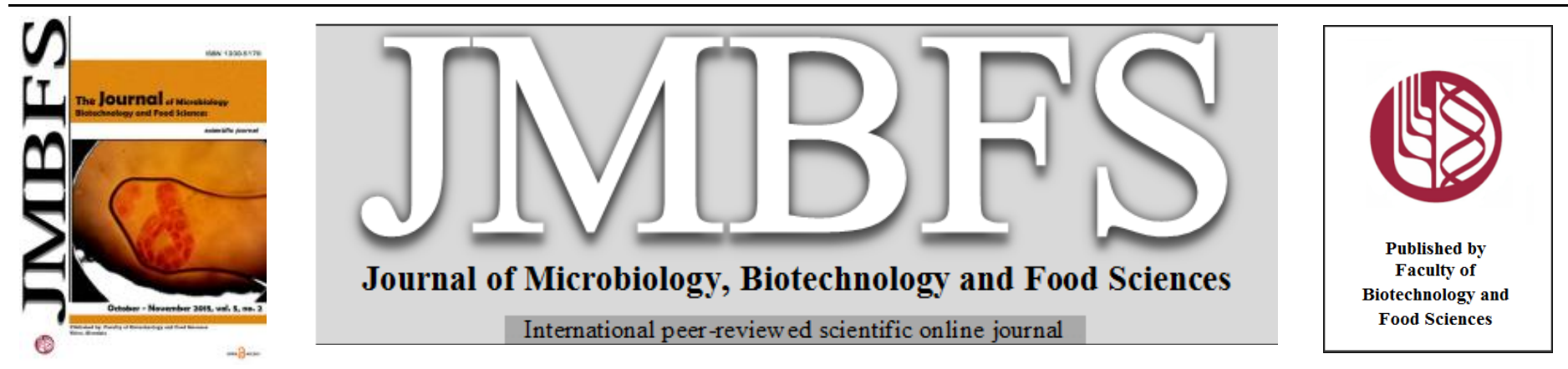

\title{
EVALUATING THE EFFICACY OF EDTA, GRAPEFRUIT SEED EXTRACT, LYSOZYME AND SODIUM BENZOATE INCORPORATED IN STARCH-GLYCEROL BASED ANTIMICROBIAL FOOD PACKAGING FILM
}

\author{
Sugandha Bhatia*, Samiksha Garg, Anita Kumari
}

\author{
Address(es): \\ Department of Biotechnology, Lovely Professional University, Jalandhar-Delhi G.T. Road (NH-1), Phagwara, Punjab, +91-1824404404 (India-144411).
}

*Corresponding author: sugandhabhatia05@gmail.com

doi: 10.15414/jmbfs.2015.5.2.120-126

\section{ARTICLE INFO}

Received 26. 3. 2015

Revised 12. 6. 2015

Accepted 23. 6. 2015

Published 1. 10. 2015

Regular article OPEN $\odot$ ACcESS

\begin{abstract}
The consortia of micro organisms obtained from contaminated food (Milkfed Verka Kheer) was effectively tested against antibacterial agents, i.e. Sodium benzoate, grinded grape fruit seed powder GSP, Lysozyme and EDTA by agar diffusion method. Bacterial inhibition by combinations using two levels from each of the three factors (EDTA, Sodium benzoate and Lysozyme) without AM films was evaluated using liquid incubation method. The levels of the agents were selected according to their permissibility standards. Statistical analysis of experimental data for their antimicrobial spectrum was carried out by multi regression analysis and framed poly-quadratic equation using coded factors and percentage contribution of antimicrobial agents was determined using Design-Expert software. Properties such as thickness, opacity, transparency, UV absorbance and efficient working $\mathrm{pH}$ of the film were also determined. The best result was observed with EDTA: Sodium benzoate: Lysozyme at $100 \mathrm{mM}$ : $100 \mathrm{mM}$ : $1000 \mathrm{IU}$ respectively at pH 9, where maximum zone of inhibition was observed that is $21 \mathrm{~mm}$. No zone of inhibition was observed using GSP as antibacterial factor limiting its widely supported usage. The work screened was imperative in performing optimization studies for the combination treatments to incorporate in starch-glycerol based active packaging film.
\end{abstract}

Keywords: Active Packaging, Antimicrobial Activity, Food Preservation, Response Surface Methodology

\section{INTRODUCTION}

Active packaging has been defined as a type of packaging that molds the packaging condition to extend shelf life and improve safety or sensory properties while maintaining the quality of the food (Jin et al., 2008). There can be many categories for active packaging techniques in order to preserve and improve quality and safety of food. These are absorbers or scavengers for $\mathrm{O}_{2}, \mathrm{CO}_{2}$, moisture, ethylene and odor; releasing systems for $\mathrm{CO}_{2}$, antioxidants, flavors, ethylene, antimicrobial agents and preservatives. Antimicrobial (AM) packaging materials are designed to extend the lag phase and reduce the growth rate of microorganisms to prolong the shelf life and maintain food quality and safety (Han, 2000). Diffusion between the packaging material and the food and partitioning at the interface are the main migration phenomena. AM food packaging is one of the special applications of active food packaging that controls inside food and atmospheric conditions actively and responsively (Muhamad, 2005).

Ethylenediaminetetraacetate (EDTA) acts as a hexadentate ligand and chelating agent. It has been widely used in cell lysis protocol as EDTA facilitate the detachment of cells from biofilm and enhances the killing of biofilm-producing microorganisms by depriving $\mathrm{Mg}^{2+}$ associated with lipo-polysaccharides and depriving $\mathrm{Ca}^{2+}$, and $\mathrm{Fe}^{2+}$, which are essential factors for microbial growth (Banin et al., 2006). Chelation of the cell membrane results in the release of the LPS (lipopolycassharide) from the Gram negative bacteria (Ko et al., 2008). EDTA can act as a food additive as it is generally recognized as safe. The average usage concentration is 100 to 300 parts per million. EDTA is being widely used in food industry to perform listed functions: sequestering metals, preventing discoloration of potato products, stabilizing vitamins, preventing discoloration of fish and shellfish and preventing flavor changes in milk (Aamoth et al., 1960; Furia, 1964). Chelating agents are observed to be nontoxic to many forms of life on acute exposure (Lanigan et al., 2002).

Grapefruit Seed extract (GSE) is a commercial product derived from the seeds of grapefruit (Citrus paradisi Macf, Rutaceae). GSE is commonly reported to have powerful antimicrobial, antifungal, antiviral and antiparasitic properties. Its capability to treat various diseases like eczema, acne, thrush, cold sore, gastric infection and ulcers is been reported (Ionescu et al., 1991; Tirillini, 2000; Heggers et al., 2002; Reagor et al., 2002). It contains large quantities of polyphenolic compounds and antioxidants (Saito et al., 1998; Shoko et al., 1999; Armando C et al., 1998). It has been found that the extract can disrupts the bacterial membrane within 15 minutes. The in vitro investigation by KrajewskaKulak et al. 2003 showed that the commercial 33\% grapefruit- water glycerol solution exerted potent antifungal activity against the yeast-like fungi strains. GSE products, $33 \%$ water-glycerol solutions are also widely used as naturopathic remedies, natural foodstuff supplements, disinfectant and sanitizing agents as well as preservatives in food and cosmetic industry. Efficiency of the ethanolic extract of GSE was also checked against 20 bacterial and 10 yeast strains (Cvetnic et al., 2004). In recent reports, artificial agents, such as benzethonium chloride, triclosan and methyl parabene, were also identified to be incorporated in commercially available products (Takeoka G et al., 2001; Sakamoto S et al., 1996).

Antimicrobial activity of lysozyme is primarily described by the lysis of the enzymes present in the cell wall of the microorganisms (Hughey et al., 1987) Lysozyme functions by attacking peptidoglycans (found in the cell walls of bacteria, especially Gram-positive bacteria) and hydrolyzing the 1,4 glycosidic bond between $\mathrm{N}$-acetylmuramic acid and $\mathrm{N}$-acetylglucosamine. Lysozyme has been widely used to preserve fresh fruits and vegetables, tofu bean curd, sea foods, meats and sausages, potato salads and varieties of semihard cheeses. The application of lysozyme has been implemented in clinical usages in the treatment of periodontitis to prevent tooth decay and also been administered in chewing gums (Proctor and Cunningham 1988). It has also been administered to patients suffering from cancer for its analgesic effect and has been used as a potentiating agent in antibiotic therapy (Verhamme et al., 1988; Le Moli et al., 1986). Their usage in AM based starch film has also been reported (Khairuddin et al., 2009).

Sodium benzoate is bacterio-static and fungi-static under acidic conditions. At higher concentrations $(2-10 \mathrm{mM})$ it enters the yeast cell in the undissociated form, and its neutralization within the cell cause a shift of the $\mathrm{pH}$ of the intracellular water by more than $1 \mathrm{pH}$ unit. Sodium benzoate also inhibited the production of phosphofructokinase in glycolysis resulting in downregulation of ATP and thus restricting growth (Krebs et al., 1983). It is most widely used as preservative in acidic foods such as salad dressings (vinegar), carbonated drinks, jams and fruit juices, pickles, and condiments. Sodium benzoate is also used in antiseptics, tobacco and as lubricant. In industry sodium benzoate is acting as corrosion inhibitor for antifreeze products. Permissible limit as food preservative is in the range of $2000 \mathrm{mg} / \mathrm{kg}$ of food (Chipley, 1983). 
Glycerol is hygroscopic by nature which has ability to absorb the moisture from atmosphere. Glycerol is used in pharmaceutical industry as plasticizer, humectants, solvent and lubricant. It was observed that its use in the food packaging and in intimate contact with food beverages cannot be a source of contamination. Glycerol is nontoxic and sweet in nature. It aids in increasing the mechanical properties of the starch based antimicrobial film (Miner, 1953).

Statistical methods had proven a promising aspect in optimizing the particular processes by considering the mutual interactions among the variables chosen and give an estimate of combined effect of these variables on final interpretation. Factorial designs are also used primarily for screening significant factors, but can also be used sequentially to model and refine a process (Chauhan et al., 2006). Response Surface Methodology (RSM) is a collection of statistical and mathematical techniques useful for developing, improving, and optimizing processes. The field of response surface methodology consists of the experimental strategy for exploring the space of the process or independent variables, empirical statistical modeling to develop an appropriate approximating relationship between the yield and the process variables, and optimization methods for finding the values of the process variables that produce desirable values of the response (Axerio et al., 2010).

In the present context, MIC of chosen antimicrobial agents were determined experimentally and application of factorial designs and RSM is envisaged using user-friendly software package Design-Expert ${ }^{\circledR}$ 8.0.7.1 software. The system response is antimicrobial activity and the system variables are antimicrobia agent's concentration of EDTA, Lysozyme and Sodium Benzoate at different liquid incubation period. The optimization method involves estimating coefficients in a mathematical model, predicting the percentage contribution of each factor to the response and checking the adequacy of the model. The keen objective of the present study was also to determine starch-glycerol based AM packaging film properties such as thickness, opacity and to screen the efficient working of the film by incorporating antimicrobial agents with differen combinations of EDTA, Grapefruit Seed Extract, Lysozyme and Sodium Benzoate by Agar diffusion bioassay.

\section{MATERIALS AND METHODS}

\section{Microbial source}

The commercial food sample, Milkfed Verka Kheer was allowed to get contaminated from the open environmental sources for 2 days. After serial dilution, spread plate technique was employed and confluent layer of cells were grown on petriplates containing Starch media and an aliquot of consortia was screened by gram staining (Gram, 1884), for Methyl Red (Clarke, 1941), Indole (MacFaddin, 1980) and Catalase (Clarke et al., 1952) test. Culture was maintained in Starch broth $(0.5 \%$ peptone, $0.3 \%$ beef extract, and $0.2 \%$ starch) at $4{ }^{\circ} \mathrm{C}$.

\section{Antimicrobials agents}

Disodium EDTA was obtained from Remeck, India. Lysozyme was obtained from Medox, India, Sodium Benzoate was purchased from Loba Chemie and Grinded Grape seed powder was dissolved in sterile water according to the concentration required. Standard stock solutions of $5000 \mathrm{IU} / \mathrm{ml}$ lysozyme, $1 \mathrm{M}$ Sodium benzoate and $100 \mathrm{mM}$ EDTA were prepared in $1 \mathrm{X}$ Citrate Buffer.

\section{Starch/antimicrobial agents film preparation}

For antimicrobial film preparation, $10.4 \%$ Starch (Sisco Research Lab, India) was dissolved in $20 \%$ ethanol as solvent and heated at $40^{\circ} \mathrm{C}$ in water bath. The combination of antimicrobial agents as listed in Table 1 were added to it and desired $\mathrm{pH}$ values of 6-9 were set and then $4 \%$ glycerol (Quailkems) was dispersed into it. $250 \mu \mathrm{l}$ of the film solution prepared from each of the set was casted onto a thin layer plate overlaid with a parafilm ${ }^{\circledR} \mathrm{M}$ and allowed to air dry overnight at room temperature. The films were peeled off and placed on agar plates having confluent culture density.

\section{Film thickness and optical measurements}

Thickness of the antimicrobial films was determined using a dial thickness screw gauge (micrometer) at five random positions on the casted circular film and the mean thickness was calculated. For optical measurement, each antimicrobial film sample of different $\mathrm{pH}$ was placed into spectrophotometer (Shimadzu) and measurements were performed using air as the reference. The light transmittance of the films was scanned from wavelength of 190 to $800 \mathrm{~nm}$. The measurement was done in triplicate and the average of three spectra was calculated. The transparency at $600 \mathrm{~nm}$ (T600) was obtained by using this formula (Han $\boldsymbol{e t}$ al., 1997). T600 $=\log \% \mathrm{~T} /$ Average Thickness. The opacity of the films was calculated by the following equation according to the method described (Gontard and Guilbert, 1994). Opacity = absorbance at 500*thickness.

\section{Bacterial inhibition testing}

Bacterial inhibition by combination of different levels of different factors (listed in Table 1) without antimicrobial films was evaluated using a liquid incubation method as described by (Appendini and Hotchkiss, 2002) and with antimicrobial films was done by agar diffusion method (Chung et al., 2003). In the agar diffusion test, each film sample was placed on the surface of a starch agar plate overlaid with the $1.5 \% \mathrm{w} / \mathrm{v}$ of agar. The seed density of overlay was approximately $10^{6} \mathrm{CFU} / \mathrm{mL}$. The agar plates were incubated at $37^{\circ} \mathrm{C}$ for $24 \mathrm{~h}$. Diameters of zone of inhibition around film specimen determines the antimicrobial activity and the diffusivity of agents in each film sample.

Table 1 Level wise distribution of antimicrobial factors incorporated in starch based antimicrobial film and in Starch Broth media for the determination of the inhibitory activities

\begin{tabular}{lccc}
\hline Factors & Levels & Experimental values & $\begin{array}{c}\text { Values for AM } \\
\text { Film }\end{array}$ \\
\hline EDTA & 3 & $0,10,20 \mathrm{mM}$ & $20 \mathrm{mM}$ \\
\hline Lysozyme & 3 & $0,1000,5000 \mathrm{IU} / \mathrm{ml}$ & $2000 \mathrm{IU} / \mathrm{ml}$ \\
\hline Sodium Benzoate & 3 & $0,100,1000 \mathrm{mM}$ & $20 \mathrm{mM}$ \\
\hline
\end{tabular}

\section{Microtitre plate assay}

For the liquid incubation test, working cultures were prepared by keeping the initial cell concentration at $10^{6} \mathrm{CFU} / \mathrm{ml}$ and incubating with different combinations of antibacterial agents at $37{ }^{\circ} \mathrm{C}, 180 \mathrm{rpm}$ and turbidity was evaluated after 1, 2, 4 and $24 \mathrm{~h}$. A Biorad iMark ${ }^{\mathrm{TM}} 96$ well microplate absorbance reader was used to monitor optical density of culture at $600 \mathrm{~nm}$ following a $10-\mathrm{s}$ shake cycle to determine MIC. $2^{3}$ sets were prepared from stock of $5000 \mathrm{IU}$ Lysozyme, $100 \mathrm{mM}$ EDTA and $1 \mathrm{M}$ Sodium benzoate to evaluate the effects of the three antimicrobials combined in starch broth as total of $300 \mu 1$ and culture was added to the wells to achieve a final concentration of $2.5 * 10^{5} \mathrm{CFU} / \mathrm{mL}$ with a positive control in which no antimicrobial agent was added and keeping starch broth as blank. The sampling was done in evaluation mode where three plate readings per one of measurement were performed and the average data of their plate readings is generated as a plate data.

\section{Statistical analysis}

Antimicrobial experiments on food spoilage causing microbes with different combinations of three factors using liquid incubation method were conducted in triplicate on different days. A general factorial design for three independent variables was used to obtain the combination of values that optimizes the response within the region of three dimensional observation spaces, which allows one to design a minimal number of experiments. The experiments were designed using the software, Design Expert Version 6.0.10 trial version (State Ease, Minneapolis, MN). The medium components (independent variables) selected for the optimization were EDTA, Sodium benzoate and Lysozyme. Regression analysis was performed on the data obtained from the design experiments. The polynomial model equation generated was determined by Fisher's test value and the proportion of variance explained by the model was given by the multiple coefficient of determination. The data was also represented graphically by surface responses showing interactions between two factors, while the other factors were fixed at values at the centre of the domain. Replicates at the centre of the domain in three blocks permit the checking of the absence of bias between several sets of experiments (Shrivastava et al., 2008). Values at a significance level of 0.05 was used for experimental design, regression and graphical analysis of the data obtained.

\section{RESULTS AND DISCUSSION}

Biochemical characterization of the microbial source and AM packaging film

Consortia of the microorganisms isolated from food spoilage source on screening were found to be positive for Methyl red test, indole test and negative for catalase test. Both gram negative and gram positive microorganisms were observed as rod and cocci shaped in compound microscope. Thicknesses observed by the micrometer screw gauge of the starch-glycerol AM films prepared with EDTA Sodium benzoate: Lysozyme at $100 \mathrm{mM}$ : $100 \mathrm{mM}$ : $1000 \mathrm{IU}$ respectively at pH 6 9 values were in the range $0.42-0.58 \mathrm{~mm}$ (Table 2). The AM films prepared were easy to dispatch from the paraffin wax and it neither roll over nor break even from the edges. All the antimicrobial film blocked the Ultra violet wavelength at 190-300nm as checked under UV Spectrophotometer. Its absorbance was observed in the range of 1-3. The result were in agreement that starch based antimicrobial film have the potential to prevent the food spoilage and retard the lipid oxidation induced by UV in food system (Bekbölet, 1990) and has tendency 
to keep the food products more perishable. Antimicrobial films developed were colorless at different $\mathrm{pH}$ ranges. AM films were also checked for opacity and transparency. With the increase in $\mathrm{pH}$ of the films prepared, opacity was found to decrease. The minimum opacity of the antimicrobial film was observed at $\mathrm{pH} 9$ i.e. 0.192. At higher $\mathrm{pH}$ values, solubility of the antimicrobial agents is high thus, enabling the formation of a homogeneous film. Therefore, more light penetrates through the film giving lower opacity values (Hewage and Vithanarachchi, 2009). Opacity is inversely proportional to the transparency so the maximum transparency was also observed of the antimicrobial film prepared with $\mathrm{pH} 9$ i.e. 2.97 (Table 2). More the transparency of the AM film better will be the appearance of the actual food texture coated with the AM film. No variation in color of the antimicrobial film was observed even when the $\mathrm{pH}$ and different antimicrobial composites were varied.

Table 2 Transparency of the antimicrobial film

\begin{tabular}{|c|c|c|c|c|c|}
\hline pH & $\begin{array}{c}\text { Average } \\
\text { Thickness } \\
(\mathrm{mm})\end{array}$ & $\begin{array}{l}\log \\
\% \mathrm{~T}\end{array}$ & T 600 & $\begin{array}{l}\text { Absorbance at } \\
500 \mathrm{~nm}\end{array}$ & Opacity \\
\hline 6 & $0.58 \pm 0.016$ & 1.5315 & 2.6405 & 0.563 & 0.325 \\
\hline 7 & $0.588 \pm 0.025$ & 0.7634 & 1.2983 & 0.568 & 0.334 \\
\hline 8 & $0.473 \pm 0.059$ & 1.3424 & 2.8381 & 0.575 & 0.272 \\
\hline 9 & $0.421 \pm 0.019$ & 1.2529 & 2.9759 & 0.456 & 0.192 \\
\hline
\end{tabular}

\section{GSP polar metabolites are not antimicrobial agents}

Our results showed that grinded grape fruit seed powder casted in polar solvent for AM film development didn't show any antimicrobial activity with 5\%,10\% and $20 \%$ concentration $(\mathrm{w} / \mathrm{v})$ when performed in triplicates. Other references had proved that $20 \%$ grinded grapefruit seed powder extracted using non-polar solvents like methanol and ethanol show the antimicrobial activity on gram positive and negative bacteria. The antibacterial activity had also been observed even in $2.1 \%(\mathrm{w} / \mathrm{v})$ concentration from the grinded grapefruit seed extracted using non polar solvents. The method of extraction influence the chemical composition of grinded grapefruit seed powder and Benzethonium Chloride component extracted from commercial GSE using chloroform had been proved as the potential antimicrobial agent. (Wentao et al., 2007; Takeoka et al., 2001; Cvetnic et al., 2004) The antimicrobial activity checked for GSP in our laboratory environmental conditions with polar solvents were not in agreement with the published results (Al- Ani et al., 2011; Dike and William, 2004). This inferred that food spoilage causing microbes may not be sensitive to the metabolites present in grinded grapefruit seed powder dissolved in polar solvent Profound results also been stated by researchers that commercial GSE products not containing any preservatives and several self-made preparations failed to show antimicrobial efficacy and concluded that antimicrobial activity being attributed to GSE is merely due to the synthetic preservative agents it contains (Woedtke et al., 1999).

Coating of the food samples (bread, apple) with antimicrobial film containing EDTA, Lysozyme and Sodium benzoate

As one of the simplest visualization assay to check for food deterioration, slices of apple without coating gets oxidized within 2 days and show signs of depletion by $6^{\text {th }}$ day but in case of the sliced apple coated with antimicrobial film, firmness retained and oxidation started from $4^{\text {th }}$ day of incubation. This reflects that antimicrobial film increases the shelf life of apple almost double the time period. In second case, the bread piece showed signs of fungal contamination at $3^{\text {rd }}$ day and had appeared brownish in comparison with the coated AM film packaging where bread texture did not change and showed signs of a consumable piece (properties are reflected in tabular form as Table 3; Supplementary Figure 1).

Table 3 Properties reflecting the coating of food slice samples (bread, apple) with antimicrobial film containing EDTA, Lysozyme and Sodium benzoate at 20 mM 2000 IU: $20 \mathrm{mM}$ respectively

\begin{tabular}{|c|c|c|c|c|}
\hline $\begin{array}{l}\text { Incubation } \\
\text { duration (in days) }\end{array}$ & $\begin{array}{l}\text { Coating of apple with starch } \\
\text { and glycerol solution }\end{array}$ & $\begin{array}{l}\text { Coating of apple with AM film } \\
\text { containing antimicrobial agents }\end{array}$ & $\begin{array}{l}\text { Coating of bread with } \\
\text { starch and glycerol solution }\end{array}$ & $\begin{array}{l}\text { Coating of bread with AM film } \\
\text { containing antimicrobial agents }\end{array}$ \\
\hline Day 1 & Firm Texture & Firm Texture & Firm Texture & Firm Texture \\
\hline Day 2 & Oxidation started & Firm Texture & Firm Texture & Firm Texture \\
\hline
\end{tabular}

\begin{tabular}{lcccc}
\hline Day 3 & Fiber content is oxidized & Firm Texture & $\begin{array}{c}\text { Color Change and start of } \\
\text { contamination }\end{array}$ \\
\hline Day 4 & Lost Fiber content & Oxidation started & $\begin{array}{c}\text { Fungal contamination } \\
\text { observed }\end{array}$ & $\begin{array}{c}\text { Fungal contamination } \\
\text { outspread }\end{array}$ \\
\hline Day 5 & Slice is Deteriorated & Fiber content is oxidized & Fungal contamination \\
outspread
\end{tabular}

Inhibition spectrum of the antimicrobial film of at different $\mathrm{pH}$ range by using Agar diffusion method

The agar diffusion test was performed to simulate the test for solid food packaging. Antimicrobial activity of the film was measured in the form of zone of inhibition. The polymer films containing only starch and glycerol as plasticizer act as negative control. The $\mathrm{pH}$ affects the viscosity of the solution, changes the degree of ionization of the most active chemicals, thereby changing the activity of the AM agents and had influential impact on the growth rate of target microorganisms (Han, 2000; Cuq et al., 1995). To measure the effect of $\mathrm{pH}$ variation on the diffusivity of three combinatorial agents chosen: EDTA, Sodium benzoate and lysozyme at concentration of $100 \mathrm{mM}: 100 \mathrm{mM}: 1000 \mathrm{IU}$, films were prepared with the desired $\mathrm{pH}$ range 6-9. All the $\mathrm{pH}$ variation studies showed effective zone of inhibition (Table 4, Figure 1) and the maximum antimicrobial inhibition was observed at $\mathrm{pH}$ 9. Maximum zone of inhibition observed was $21 \mathrm{~mm}$ and the ratio of the diameter of inhibition zone to the diameter of the film specimen $(11 \mathrm{~mm})$ was 2.90 indicating that antimicrobial agents were easily diffused from starch based film and plasticizer used as negative control didn't exhibit any antimicrobial activity alone (not shown).
Table 4 The ratio of the diameter of inhibition zone to the diameter of the film specimen $(11 \mathrm{~mm})$ at different $\mathrm{pH}$ range $(6-9)$

\begin{tabular}{lcc}
$\begin{array}{l}\text { pH of the } \\
\text { film }\end{array}$ & $\begin{array}{c}\text { Diameter of zone of } \\
\text { inhibition }(\mathbf{m m})\end{array}$ & $\begin{array}{c}\text { Film antimicrobial } \\
\text { efficiency }\end{array}$ \\
\hline 6 & $27-11=16$ & 2.45 \\
\hline 7 & $26-11=15$ & 2.36 \\
\hline 8 & $28-11=17$ & 2.54 \\
\hline 9 & $32-11=21$ & 2.9 \\
\hline
\end{tabular}




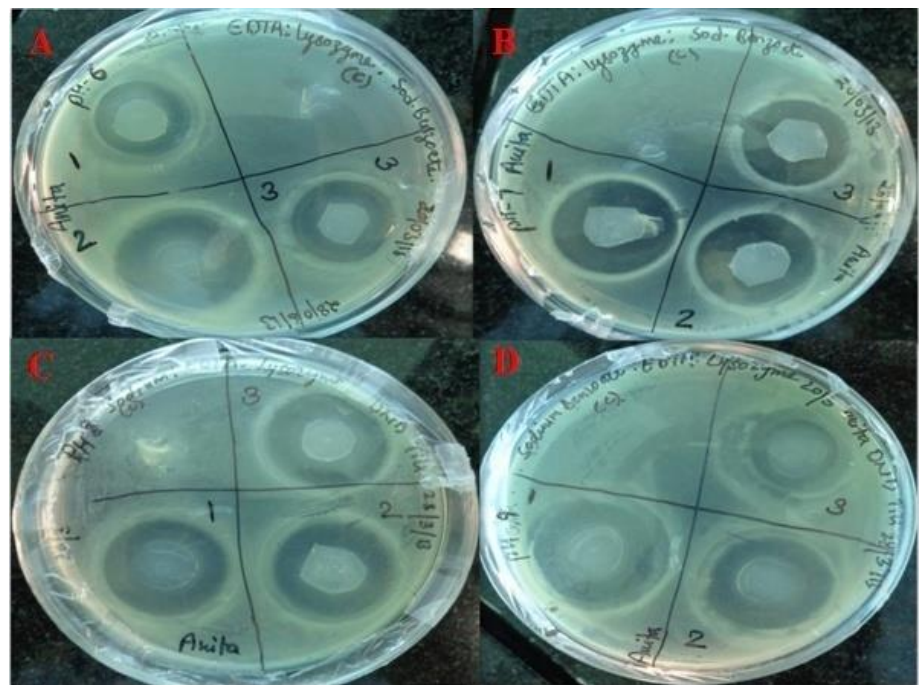

Figure 1 Results of bacterial growth inhibition by agar diffusion method. Inhibition effectiveness of the antimicrobial film of EDTA, Sodium benzoate and lysozyme at $20 \mathrm{mM}$ : $20 \mathrm{mM}$ : $2000 \mathrm{IU}$ at different $\mathrm{pH}$ range 6-9, Average diameter observed for A: $\mathrm{pH} \mathrm{6,16} \mathrm{mm.} \mathrm{B:} \mathrm{pH} \mathrm{7,} 15$ mm. C: $\mathrm{pH}$ 8, $17 \mathrm{~mm}$. D: $\mathrm{pH}$ $9,21 \mathrm{~mm}$.

Statistical analysis of combined effects of EDTA, Lysozyme and Sodium Benzoate on spoilage micro organism in starch media

The spectroscopic results obtained at 600nm were evaluated using Design Expert 8.0.7.1. Antimicrobial responses of combinatorial antimicrobial agents in $2^{3}$ sets (i.e. 2 levels for three factors) (Table 1) were measured at 1, 2, 4 and $24 \mathrm{~h}$ of incubation and was represented by a full quadratic model with 7 coefficients for three variables (Table 5) describing interaction terms and relationships between responses and experimental factors to represent the polynomial quadratic equation:

$$
\mathrm{\eta} j=\beta j_{0}+\sum_{i=1}^{n} \beta j_{i} X_{i}+\sum_{i=1}^{n-1} \sum_{j=i+1}^{n} \beta j_{i j} \mathrm{X}_{i} \mathrm{X}_{j}
$$

where $\eta j$ is the dependent variable; $\beta j_{0}$ is the constant coefficient; $X_{i}$ are the coded independent variables; $\beta j_{\mathrm{i}}$ are the linear coefficients and $\beta j_{\mathrm{ii}}$ are the quadratic coefficients.

The percentage contributions of the antimicrobial agents changed with the increase in incubation period (Table 6). At $1 \mathrm{hr}$, maximum contribution as antimicrobial agent was observed by C (lysozyme) component i.e. $45.41 \%$, but at $2^{\text {nd }}$ hour, the maximum percentage contribution were observed by AC component which were EDTA-Lysozyme association i.e.41.27\%. It can be inferred that in $1^{\text {st }}$ hour, lysozyme showed its activity depending on its higher molar concentration and in $2^{\text {nd }}$ hour, its show synergistic effect with EDTA. In $4^{\text {th }}$ and $24^{\text {th }}$ hour incubation the maximum percentage contribution as antimicrobial agent was observed by AB (EDTA and Sodium benzoate) component that was $42.51 \%$ and $36.34 \%$ respectively reflecting sodium benzoate-EDTA association along with
lysozyme-EDTA association (which places as second highest in their percent contribution to antibacterial activity) act in concordance upto 24 hour. Its regression value is 0.96 . This means that this model is fully significant at $24 \mathrm{hr}$.

Table 5 Coefficients of the quadratic model for three variables: sodium benzoate $(100 \mathrm{mM}$ and $1000 \mathrm{mM})$, lysozyme $(1000$ and $5000 \mathrm{IU} / \mathrm{ml})$ and EDTA concentrations (100 and $1000 \mathrm{mM}$ ) as determined by inhibition assays after incubation at $37^{\circ} \mathrm{C}$ for $1,2,4$ and $24 \mathrm{~h}$

\begin{tabular}{lcccc}
\hline Factors & $\mathbf{1 ~ h}$ & $\mathbf{2} \mathbf{~ h}$ & $\mathbf{4} \mathbf{h}$ & $\mathbf{2 4} \mathbf{~ h}$ \\
\hline Intercept & -0.111 & 0.382 & -0.186 & -0.252 \\
\hline A-EDTA & -0.06 & 0.001 & 0.058 & -0.09 \\
\hline B-Sodium benzoate & 0.038 & 0.012 & 0.064 & -0.046 \\
\hline C-Lysozyme & 0.228 & 0.175 & 0.098 & 0.137 \\
\hline AB & 0.161 & 0.007 & -0.118 & 0.205 \\
\hline AC & -0.057 & 0.186 & -0.038 & -0.196 \\
\hline BC & 0.108 & 0.002 & 0.009 & -0.035 \\
\hline $\mathrm{R}^{2}$ & 0.85 & 0.85 & 0.98 & 0.96 \\
\hline
\end{tabular}

Table 6 Percentage contribution of three antimicrobial agents: sodium benzoate $(100 \mathrm{mM}$ to $1000 \mathrm{mM})$, lysozyme $(1000$ and $5000 \mathrm{IU} / \mathrm{ml})$ and EDTA concentrations $(100$ and $1000 \mathrm{mM})$ is determined by inhibition spectrum after incubation at $37^{\circ} \mathrm{C}$ for $1,2,4$ and $24 \mathrm{~h}$

\begin{tabular}{lcccc}
\hline \multirow{2}{*}{ Term } & \multicolumn{2}{c}{ Contribution } & & \\
\cline { 2 - 5 } & $\mathbf{1} \mathbf{~ h}$ & $\mathbf{2} \mathbf{~ h}$ & $\mathbf{4} \mathbf{~}$ & $\mathbf{2 4} \mathbf{~}$ \\
\hline A-EDTA & 3.11 & 0.15 & 10.31 & 7.02 \\
\hline B-Sodium benzoate & 1.27 & 2.66 & 12.41 & 1.81 \\
\hline C-Lysozyme & 45.41 & 38.66 & 28.99 & 16.22 \\
\hline AB & 22.74 & 1.51 & 42.51 & 36.64 \\
\hline AC & 2.85 & 41.27 & 4.44 & 33.5 \\
\hline BC & 10.14 & 0.36 & 0.26 & 1.04 \\
\hline ABC & 14.49 & 15.36 & 1.08 & 3.77 \\
\hline
\end{tabular}

The three-dimensional (3-D) response surfaces were plotted on the basis of the model equation to investigate the interaction among two antimicrobial variables and to determine the optimum concentration of each factor for maximum antimicrobial activity by liquid culturing. The response surfaces shown in Figure 2 were based on the final model, holding one variable constant at its optimum level, while the other two within their experimental range. The shape of the response surface implies synergistic interaction between EDTA and Sodium Benzoate was stronger than between EDTA and Lysozyme. 


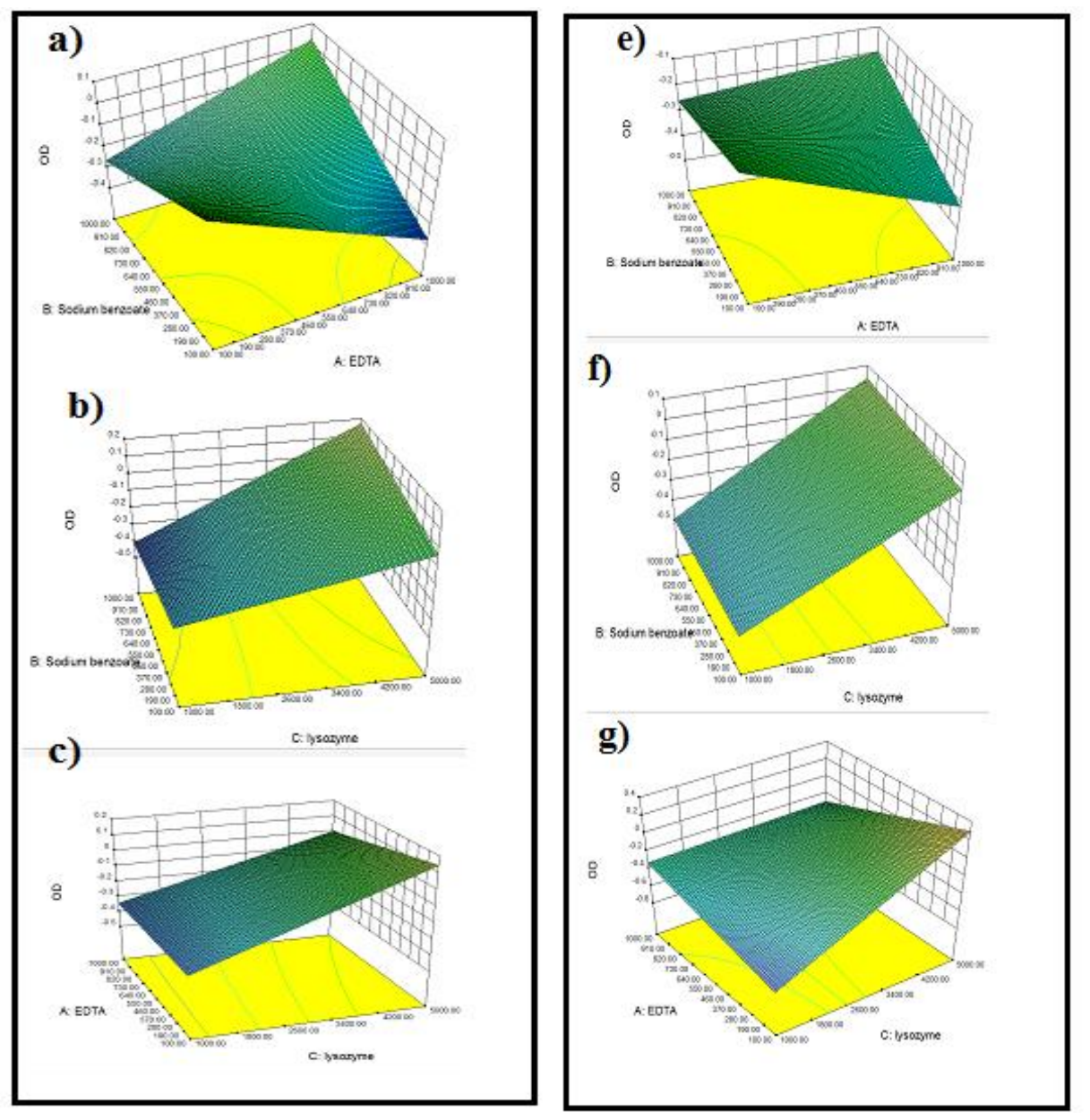

Figure 2.1 Response surface plot at $1 \mathrm{hr}$ and $2 \mathrm{hr}$ respectively: - a, e) effect of antimicrobial agents EDTA and sodium benzoate when lysozyme was at zero level. B, f) Effect of antimicrobial agents sodium benzoate and lysozyme when EDTA was at zero level. C, g) Effect of antimicrobial agents EDTA and lysozyme when sodium benzoate was at zero level.

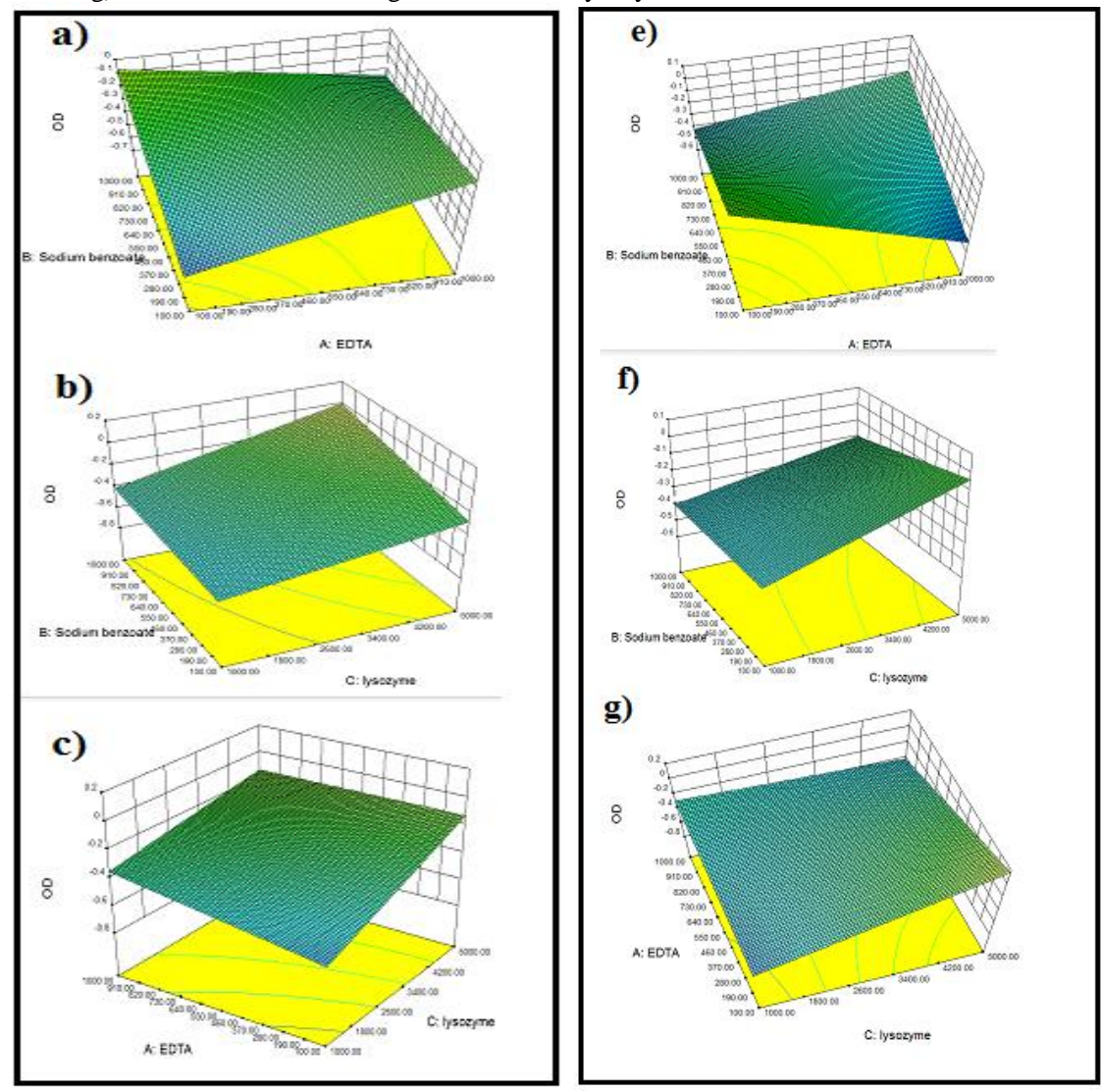

Figure 2.2 Response surface plot at $4 \mathrm{hr}$ and $24 \mathrm{hr}$ respectively: - a, e) effect of antimicrobial agents EDTA and sodium benzoate when lysozyme was at zero level. b, f) Effect of antimicrobial agents sodium benzoate and lysozyme when EDTA was at zero level. c, g) Effect of antimicrobial agents EDTA and lysozyme when sodium benzoate was at zero level. 


\section{CONCLUSION}

The use of starch in combination with sodium benzoate, EDTA and Lysozyme had a great potential in antimicrobial food packaging to reduce post-process growth of food pathogens and spoilage causing micro-organisms. The purpose of this research is to develop an antimicrobial consumable starch-based film with glycerol as plasticizers to reduce brittleness and to improve the flexibility of active packaging which ensures to prolong the shelf life of food products maintaining its quality and integrity. It was found that the film developed with GRAS AM agents within their permissible limits is effective towards inhibition of food spoilage causing microbes doubling its shelf life. Statistical analysis using Design-Expert software showed that the percentage contribution of the AM agents changed with the increase in incubation period in which lysozyme acts as proactive component and the coefficients obtained can be fit for drafting polyquadratic equation to optimize the effective combination of the three ingredients used for making biofilm against food spoilage causing micro organisms.

\section{REFERENCES}

AAMOTH, H., BUTT, F. 1960. Maintaining food quality with chelating agents. Annals New York Academy of Sciences, 526-531. http://dx.doi.org/10.1111/j.1749-6632.1960.tb20050.x

AL-ANI, WN., TAWFIK, NOM., SHEHAB, EY. 2011. Antimicrobial activity of grapefruit seeds extracts (In vitro study). Al-Rafidain Dental Journal, 11(2), 341345.

APPENDINI, P., HOTCHKISS, J H. 2002. Review of antimicrobial food packaging. Innovative Food Sciences and Emerging Technologies, 3(2), 113-126. http://dx.doi.org/10.1016/S1466-8564 (02)00012-7

ARMANDO, C., MAYTHE, S., BEATRIZ, N P. 1998. Antioxidant activity of grapefruit seed extract on vegetable oils. Journal Science of Food Agriculture, 77(4), 463-467. $\quad$ http://dx.doi.org/ 10.1002/(SICI)10970010(199808)77:4<463::AID-JSFA62>3.0.CO;2-1

AXERIO, J., WANG, Q., LACCARINO, G. 2010. Constructing Response Surfaces Using Imperfect Function Evaluations, 51 ${ }^{\text {st }}$ AIAA/ASME/ASCE/AHS/ASC Structures, Structural Dynamics and Materials Conference. April. http://dx.doi.org/10.2514/6.2010-2925

BANIN, E., BRADY, K., GREENBERG E. 2006. Chelator induced dispersal and killing Pseudomonas aeruginosa cellsina biofilm. Applied Environmental Microbiology, 72(3), 2064-2069. http://dx.doi.org/10.1128/AEM.72.3.2064 $\underline{2069.2006}$

BEKBÖLET, M. 1990. Light effects on food. Journal of Food Protection 53, 430-440.

CHAUHAN, K., TRIVEDI, U., PATEL, KC. 2006. Application of response surface methodology for optimization of lactic acid production using date juice. Journal of Microbiology \& Biotechnology, 16(9), 1410-1415.

CHIPLEY, JR. 1983. Sodium benzoate and benzoic acid. In: Branen AL, Davidson PM, eds. Antimicrobials in foods New York, 11-35. http://dx.doi.org/10.1201/9781420028737.ch2

CHUNG, D., PAPADAKIS, SE., YAM, K L. 2003. Evaluation of a polymer coating containing triclosan as the antimicrobial layer for packaging materials. International Journal of Food Science and Technology, 38, 165-169. http://dx.doi.org/10.1046/j.1365-2621.2003.00657.x

CLARKE, H., COWAN S. 1952. Biochemical methods for bacteriology. Journal of General Microbiology, 6, 187-197. http://dx.doi.org/ 10.1099/00221287-6-1-2-187 CLARKE, H., KIRNER, W. 2003. Methyl Red. Organic Syntheses, 1, 374 http://dx.doi.org/10.1002/0471264180.os002.11

CUQ, B., AYMARD, C., CUQ JL, GUILBERT, S. 1995. Edible packaging films based on fish myofibrillar proteins: Formulation and functional properties. Journal of Food Science, 60, 1369-1374. http://dx.doi.org/10.1111/j.1365 2621.1995.tb04593.x

CVETNIĆ, Z., VLADIMIR-KNEZEVIĆ, S. 2004. Antimicrobial activity of grape fruit seed and pulp ethanolic extract. Acta Pharmaceutica, 54, 243-250.

DIKE, OU., WILLIAM, FF. 2004. Effect of nisin in combination with EDTA sodium lactate and potassium sorbate for reducing Salmonella on whole and freshcut cantaloupe. Journal of Food Protection, 67, 2143-2150.

Furia, T. 1964. EDTA in Foods -A Technical Review. Food Technology, 18:12, 1874-1882.

Gram, C. 1884. Fosrtschr. Medicine, 2, 185.

GONTARD, N., GUILBERT, S. 1994. Biopackaging: Technology and properties of edible and /or biodegradable material of agricultural origin. Food packaging and preservation, 159-181. http://dx.doi.org/10.1007/978-1-4615-2173-0_9

HAN, JH. 2000. Antimicrobial Food Packaging. Food Technology, 5 4(3):56-65.

HAN, J., FLOROS, J. 1997. Casting antimicrobial packaging films and measuring their physical properties and antimicrobial activity. Journal of Plastic Film and Sheeting, 13, 287-298. http://dx.doi.org/10.1177/875608799701300405

HEGGERS, JP., COTTINGHAM, J., GUSMAN, J., REAGOR, L., MCCOY, L. CARINO, E., COX, R., ZHAO, JG. 2002. The effectiveness of processed grape fruit-seed extract as an antibacterial agent: II. Mechanism of action and in vitro toxicity. Journal of alternative and complementary medicine, 8, 333-340. http://dx.doi.org/10.1089/10755530260128023
HEWAGE S., VITHANARACHCHI SM. 2009. Preparation and characterization of biodegradable polymer films from cowpea (Vignaunguiculata) protein isolate. Journal of the National Science Foundation of Sri Lanka, 37(1), 53-59. http://dx.doi.org/10.4038/jnsfsr.v37i1.457

HUGHEY, VL., JOHNSON, EA. 1987. Antimicrobial activity of Lysozyme against bacteria involved in food spoilage and food-borne disease. Applied Environmental Microbiology, 53, 2165-2170.

IONESCU, G., Kieh, 1 R., WICHMANN-KUNZ, F., WILLIAMS C, BAUM, L., LEVINE, S. 1991. Oral citrus seed extract in atopic eczema: In vitro and In vivo studies on intestinal microflor. Journal of Orthomolecular Medicine, 5, 230-238. JIN, T., ZHANG, H. 2008. Biodegradable polylactic acid polymer with nisin for use in antimicrobial food packaging. Journal of Food Science, 73, 127-134 http://dx.doi.org/10.1111/j.1750-3841.2008.00681.x

KRAJEWSKA-KULAK, E., LUKASZUK, C., NICZYPORUK, W. 2003 Antifungal activity of $33 \%$ grape fruit water glycerol solution, Journal of the European Academy of Dermatology and Venerology, 17(4), 486-487 http://dx.doi.org/10.1046/j.1468-3083.2003.00614_12.x

KHAIRUDDIN, N., MUHAMAD II. 2009. Antimicrobial (AM) Effects OF Starch-Based Film Incorporated With Lysozymes. Pertanika Journal of Sciences and Technology, 17(1), 1-8.

KO, KY., MENDONCA, AF., AHN DU. 2008. Effect of Ethylene diamine tetraacetate and Lysozyme on the Antimicrobial Activity of Ovotransferrin against Listeria monocytogenes. Poultry Science, 87, 1649-1658. http://dx.doi.org/10.3382/ps.2007-00521.

KREBS, HA., WIGGINS, D., STUBBS, M., SOLS, A., BEDOYA, F. 1983. Studies on the mechanism of the antifungal action of benzoate. The Biochemical Journal, 214(3), 657-63.

Lanigan, RS., Yamarik, TA., Andersen, FA. 2002. Final report on the safety assessment of BHT. International Journal of Toxicology, 21, 95-142.

LEMOLI, S., PAGANELLI, R., SIRIANNI, MC., NISINI, R., QUINTI, I, SEMINARA, R., D'AMELIO, R., AIUTI, F. 1986. Gli effetti in vitro de lisozima su alcune fuzioni specifiche e non specifiche del sistema immunitario. Boll. Ist. Sieroterap. Milan, 65, 283-289.

MAC FADDIN, JF. 1980. Biochemical Tests for Identification of Medica Bacteria, Williams \& Wilkins 173-183.

MINER, CS. 1953. Glycerol. American Chemical Society Monograph, Reinhold Publishing Corporation. 117.

MUHAMAD II. 2005. Study of an active antimicrobial system using a Bioswitch concept. Thesis

PROCTOR, VA., CUNNINGHAM, RE. 1988. The chemistry of Lysozyme and its use as a food preservative and a pharmaceutical. Critical Reviews in Food Science and Nutrition, 26(4),

395. http://dx.doi.org/10.1080/10408398809527473

REAGOR, L., GUSMAN, J., MCCOY, L., CARINO, E., HEGGERS, JP. 2002 The effectiveness of related grape fruit-seed extract as an antibacterial agent: I. An in vitro agar assay. Journal of alternative and complementary medicine, 8(3), 325-332. http://dx.doi.org/10.1089/10755530260128014

SAITO, A., HOSOYAMA, H., ARIGA, T., KATAOKA, S., YAMAJI, N. 1998. Antiulcer activity of grape seed extract and procyandies. Journal Agriculture of Food Chemistry, 46(4), 1460-1464. http://dx.doi.org/10.1021/jf9709156

SAKAMOTO, S., SATO, K., MAITANI, T., YAMADA, T. 1996. Analysis of components in natural food additive grape fruit seed extract by HPLC and LC/MS, Eisei ShikenjoHokoku, 11438-42.

TAKEOKA, G., DAO, L., WONG, R Y., LUNDIN, R., MAHONEY, N. 2001 Identification of Benzethonium chloride in commercial grape fruit seed extracts. Journal Agriculture of Food Chemistry, 49(7), 3316-3320. http://dx.doi.org/10.1021/jf010222w

SHOKO, T., SOICHI, T., MEGUMI, M., ERI, F., JUN, K., MICHIKO, W. 1999. Isolation and identification of an antimicrobial compound from gape and its application to food. Nippon Nogeikagaku Kaishis, 73, 125-128.

SHRIVASTAVA, A., BAJAJ, I., SAUDAGAR, P., SINGHAL, R. 2008. Media Optimization for the Production of $\gamma$-Linolenic Acid by Cunninghamella echinulata var elegans MTCC 552 Using Response Surface Methodology International Journal of Food Engineering, 4(2), 1-34 http://dx.doi.org/10.2202/1556-3758.1178

TIRILLINI, B. 2000. Grapefruit: the last decade acquisitions. Fitoterapia, 71, 2937.

TAKEOKA, G., DAO, L., WONG, R., LUNDIN, R., MAHONEY, N. 2001. Identification of Benzethonium Chloride in Commercial Grape fruit Seed Extracts. Journal Agriculture Food Chemistry, 49(7), 3316-3320. http://dx.doi.org/10.1021/jf010222w

VERHAMME, I., RACCHELLI, L., LAUWERS, A. 1988. Lysozyme (NAcetylmuramyl- $\beta(1>4)$ Glycanohydrolase EC3.21.17). International Pharmacy Journal, 2, 129-132.

WENTAO, X., WEI, Q., KUNLUN, H., FENG, G., JIAJIA, Y., HENG, Z. YUN, BO L. 2007. Antibacterial effect of grape fruit seed extract on food borne pathogens and its application in the preservation of minimally processed vegetables. Post Harvest Biology and Technology 45, 126 133. http://dx.doi.org/10.1016/j.postharvbio.2006.11.019 
WOEDTKE, TV., SCHLÜTER, B., PFLEGEL, P., LINDEQUIST, U., JÜLICH, WD. 1999. Aspect of the antimicrobial efficacy of grape fruit seed extract and its relation to preservative substances contained. Pharmazie, 54, 452-456. 